\title{
Two views of an inevitable catastrophe that did not take place: Werner Herzog and Daniel Maximin on Guadeloupe, 1976
}

\author{
Jessica Stacey* \\ The Queens College, Oxford University, Oxford, UK
}

*Email: jessica.stacey@queens.ox.ac.uk

This article interrogates the mechanics of catastrophe narration. Rather than doing so through the examination of a celebrated historical or fictional catastrophe, it takes two responses to a catastrophe which did not, in the end, take place: the 1976 non-eruption of the volcano La Soufrière on Guadeloupe. The first is Werner Herzog's La Soufrière which, from an outsider's perspective, stages fascination and disappointment on behalf of a global audience. The second, Guadeloupian author Daniel Maximin's 1987 novel Soufrières, uses multiple narrative strands to represent the non-eruption, and thus unlock a longer history of local and global colonial and postcolonial violence. The fact that there was, in fact, no spectacular climax to the events of 1976 permits a focus on other, "slower" narratives which might have been obscured by clouds of gas and outpourings of lava.

Keywords: catastrophe; Guadeloupe; Daniel Maximin; Werner Herzog; Rob Nixon; volcanoes August 1976, Basse-Terre, Guadeloupe. La Grande Soufrière, the island's volcano, is expected to explode with the force of "five or six atomic bombs" (Herzog 1977). The surroundings have been evacuated, but one inhabitant, a peasant living on the slopes of La Soufrière, refuses to leave. Reading this story in a German newspaper, Werner Herzog decides to set out for the island to secure an interview with this man and film the abandoned town. He calls the film La Soufrière: Warten auf eine unausweichliche Katastrophe (La Soufrière: Waiting for an inevitable catastrophe). The volcano does not, however, erupt. "It will always remain a mystery why there was no eruption", states Herzog at the close of his film. "Never before in the history of volcanology were signals of such magnitude measured, and yet nothing happened" (Herzog 1977). Nevertheless, the resultant documentary, unlike the volcano, is no damp squib. In this article, I ask how Herzog's report on "an inevitable catastrophe which did not take place" is 
revelatory of our narrative investment in catastrophes that $d o$. What do narratives of catastrophe privilege, and what do they obscure?

What -- or whom? In Slow Violence and the Environmentalism of the Poor, Rob Nixon (2011) argues that media obsession with spectacular images of catastrophe and the high-drama narratives surrounding them renders invisible less spectacular violence (what he describes as "slowly unfolding" or "attritional" catastrophes [2, 9]). Herzog's documentary can be used to craft a response -- albeit partial -- to the question at the heart of Nixon's work: "How do we make slow violence visible yet also challenge the privileging of the visible?" (15). How do we avoid simply transforming stories of slow violence into the kinds of narrative and image that digital and visual media already exalt? Herzog's film is a unique document of the global response to local catastrophes. At the end of its 30 minutes, Herzog as the film's narrator tells us that the "picture [ ... ] ended a little bit embarrassing". This record of an embarrassment which would usually be allowed to slip from history reveals the complex temporal nexus around catastrophe.

Herzog is not the only artist to have engaged with that summer of expectation. Guadeloupian writer Daniel Maximin’s (1987) novel Soufrières, which represents a group of eight friends awaiting the same non-event, uses the failed eruption to explore the situation of the French Antilles in the 1970s and its relationship to global decolonization and civil rights struggles. Nixon is a champion of "writer-activism", particularly in the novel as a medium of "slowness" as against spectacular image. He challenges "the privileging of the visible"; "what happens", he asks,

when we are unsighted, when what extends before us $[\ldots]$ remains invisible? [ ... ] Writing can challenge perceptual habits that downplay the damage slow violence inflicts and bring into imaginative focus apprehensions that elude 
sensory corroboration. The narrative imaginings of writer-activists may thus offer us a different kind of witnessing: of sights unseen. $(2011,15)$

Nixon assigns the filmmaker a role, alongside the writer or digital activist, in helping "embattled communities [ ... ] broadcast their inhabited fears" (16). However, he does not seem to regard this role as being of the same order as the work of novelists and other writer-activists -- a hierarchy this article seeks to challenge. The novel and film can both challenge dominant narratives of catastrophe through plurality of voices -offering competing narratives, and foregrounding the fictionality of those narratives. Chris Bongie (1994) has identified an "imperative of a non-parodic life" in Maximin's novels - one that is always unfulfillable (637) -- and the parody of processes of narrativisation will be a key focus in the current article. In Herzog's documentary, we are offered a parody of the film that would have been made of the eruption, until its non-event is revealed and the focus shifts to the "neglect and oblivion" suffered by those citizens who did not consider their own lives worth saving. Maximin's Soufrières, meanwhile, offers us the geological, political and literary landscape of a Guadeloupe in which the island's volcano is read as inescapably metaphorical, even as the various narrative voices (including that of the volcano itself) critique this metaphorisation of a natural catastrophe. The volcano is represented as at once the symbol through which historical and personal events -- the slave trade, the massacre of Mé ' $67,{ }^{1}$ the independence movement or the deaths of parents -- are understood as meaningful and connected, and as an ungraspable "real" which is the location of violence that, flowing as it does from mysterious subterranean forces, escapes meaning. Maximin's novel places the opportunist narratives of politicians and bureaucrats alongside anguished or joyful creative projects. As Marie-Gabriel, one of the protagonists (who is herself writing a novel about the mother who died giving birth to her), notes, dozens of 
Guadeloupians "are blackening the pages of their notebooks over La Soufrière" (Maximin 1987, 61). ${ }^{2}$ The novel thus foregrounds the way in which we seek to make meaningful stories out of societal and personal catastrophes. Further, it prompts us to reflect on different kinds of narrative. Which ways of telling of and reading catastrophe are pernicious or obfuscatory? Which are necessary and life-giving? How we can strive to make use of stories whilst recognising their inherent fictiveness? ${ }^{3}$

As part of a challenge to what he calls the ever-shortening "story unit" of our Internet age, Nixon draws a distinction between structural violence and slow violence. The similarity between the two concepts, he writes, lies in their shared aim to widen "the field of what constitutes violence", since analyses of structural violence could "range from the unequal morbidity that results from a commodified healthcare system, to racism itself" (Nixon 2011,). 10The concept of slow violence is intended to address what Nixon perceives as a tendency in analyses of structural violence to concentrate exclusively on the synchronous. To analyse slow violence, on the other hand, is to account for change, development, and links between events, although the focus is still on hidden or unacknowledged suffering. To give Nixon's example, the concept of slow violence can challenge statements such as, "during our dozen years [in Vietnam] the U.S. killed and helped kill at least 1.5 million people" (13-14), by demanding that the "story unit" be expanded to take in the ongoing effects of Agent Orange. I understand the exhortation to examine slow violence as a call for a change in emphasis, rather than a rejection of analyses of structural violence. To think the events of Mé '67 in terms which unite the concepts of structural and slow violence would be to urge a "story unit" which takes in an expanded past, present, and future of the event. The "past" here would include the longstanding degradations which motivated the demonstrations, and which made the May 27th anniversary of the abolition of slavery in Guadeloupe such a 
flashpoint. The "present" is the massacre, now accepted as a human catastrophe, although the authorities and (some suspect) victims' families allowed a silence to descend which has prevented the dead from being identified. ${ }^{4}$ The "future" would include trauma for individuals involved in or connected to the massacre, as well as the nefarious effects of social tensions and distrust that arise from a massacre perpetrated and then unaddressed. These last effects can be traced in the actions of Toussaint, a character in Maximin's novel traumatised by his involvement in the Mé ' 67 protests, who stigmatises those who, like his friend Rosan, access government agricultural subsidies (Maximin 1987, 83). In Toussaint's story, we can see how the slow violence resulting from supposedly discrete events can be reabsorbed into social and economic relations and thereby encourage structural inequality. Essentially, the concept of slow violence helps us bring together stories of personal experiences of catastrophe, including trauma, stories belonging to the disputed domains of cultural and transgenerational trauma, and measurable if not-readily-visible inequalities and structural violence.

Both the texts considered here take advantage of the non-event of the eruption, the spectacular visuals of which would have been "eye-catching and page-turning" (Nixon 2015, 3), in order to encourage us to see the possibility of the eruption as part of a story unit which tells of particular subjects made more vulnerable to catastrophe as a result of structural violence -- which might itself be considered as a manifestation of the "slow violence" of slavery. If Herzog's film stops at this suggestion, Maximin, as we will see, goes further, offering his novel as a self-conscious intervention into the canon of Antillean literature and culture that links it with precarious societies worldwide. In so doing, the novel asks us to consider Mé ' 67 and its traumas, vulnerability to geological cataclysm, slavery, and the 1976 Soweto massacres in South Africa, as part of the same 
"story unit". Nixon calls for writers to devise "iconic symbols that embody amorphous calamities as well as narrative forms that infuse those symbols with dramatic urgency" (2011, 10). Herzog's film and Maximin's novel both show us what a catastrophe which does not take place can reveal about how the story unit of catastrophe is usually constructed. They use the device of a thwarted catastrophe-story to shift the focus to slow violence. In different ways, they offer what Bongie, in the title of his article on Maximin, calls "The (Un)Exploded Volcano" -- one which nonetheless always threatens -- as a potent symbol of the slowly unfolding, attritional, amorphous calamity that is the legacy of colonialism in the Caribbean.

\section{Catastrophe and responsibility}

Scientists responsible for predicting catastrophe are required to be ultra-cautious regarding the risk of casualties, at the same time as avoiding disruption to the economic life of the region concerned. This is the difficult balance upon which the argument was couched between those overseeing the evacuation of Basse-Terre and their critics: since the feared eruption did not occur, was the evacuation and resultant economic disruption a necessary precaution, given the information available at the time, or an overreaction? ${ }^{5}$ Volcanologists and the civil servants who work with them cannot operate independently of the power of narrative, and the feeling that past catastrophes are being echoed or repeated in present events. Astrid Erll (2008) has from a Media Studies perspective suggests that "premediation", or what literary scholars might think of as the intertextuality, of any given catastrophe (392-393) exerts a powerful influence on its perception. As Herzog and Maximin both suggest, Guadeloupian scientists, politicians and citizens were motivated by a desire not to repeat the mistakes of Martinique's deadly Mount Pelée eruption of 1902 (Maximin 1987, 174-177). A bitter media war broke out between those who had counselled evacuation and Haroun Tazieff, a 
celebrated Polish/Belgian/French volcanologist who headed the French Service de Volcanologie at the beginning of the affair, but was sacked during the evacuation by Claude Allègre, his superior at the Institut du Physique du Globe de Paris (IPG), (Tazieff had recommended on September 1, against official advice, that Guadeloupians return to their homes on Basse-Terre. $)^{6}$

If we are to believe Tazieff, Herzog is caught up in a costly, panic-driven "pure mise en scène" (Beauducel 2015). According to a committee of experts convened in November 1976, which advised that the population could return safely, evacuation had been the only reasonable response to the scientific observations made -- even if some of those observations later turned out to be mistaken. A fear of repeating the story of the deadly eruption of 1902 could be blamed for the supposedly unnecessary Guadeloupe evacuation of 1976. In turn, consciousness of "l'erreur 76" (Beauducel calls it a "psychose" within the world of volcanology) was in turn a direct cause of casualties in the 1980 Mount St. Helen eruption, which Tazieff had publicly dubbed "a little Soufrière", in addition to being a key factor in the Columbian government's fatally slow response to warnings from the scientific community during the 1985 eruption of the Nevado del Ruiz, which killed 23,000 people (this time despite warnings from Tazieff). In these instances, the lack left by the non-eruption of La Soufrière in the narrative of 1976 allowed the "story" of the economic losses caused by evacuation to gain primacy, with catastrophic consequences (see Beauducel 2015, for analysis of these and other incidents influenced by the 1976 polemic). I must emphasise that, in tracing the links between these events, I am not seeking to apportion blame to any of the actors, but to highlight the power that premediating catastrophe stories assume, given competing demands and imperfect knowledge of causation.

Herzog's bald statement that "it will always remain a mystery why there was no 
eruption" masks what was in fact a vitriolic scientific debate over how the signs displayed by the volcano should have been interpreted. Those who oversaw the evacuation of Basse-Terre were placed in an impossible position and were attacked, not for deaths caused, but for deaths wrongly projected. ${ }^{7}$ Herzog, too, finds his own attempt at journalism on the edge marred by "something pathetic" and "embarrassing". Both Herzog and Maximin manage to begin with this cycle of calculation and embarrassment, ultimately to escape it. They do this by focusing respectively on those who, in refusing evacuation, would not have been saved had the eruption happened, and those who made a complicated narrative investment in the eruption, which almost amounted to a desire for it to take place. Such stories, swamped by post-hoc debates about "unnecessary" disruptions to everyday life, provide examples of the diversity of narratives of slow violence which can be told through and around catastrophes, in both literature and film. But to register this fully, one needs to relinquish a fixation on either the spectacular event, or the "embarrassing" non-event.

\section{Narrative premediation, political agendas}

In this section, I will discuss how the film and the book raise the problem of narrative investments in catastrophe. The two subsequent sections will examine how the two texts address this problem through multiplying narratives.

In the first half of La Soufrière: Waiting for an Inevitable Catastrophe, Herzog and his two cameramen tour deserted Basse-Terre. The anachronicity of the town is signalled by a shot of the traffic lights which, Herzog tells us, fleeing officials forgot to switch off, and which we see marking out a now-irrelevant temporal rhythm. The tone set by the soundtrack and the commentary is elevated, being both mystic/prophetic (Herzog describes the sea as full of snakes which drowned fleeing the tremors) and 
elegiac. The team has shot only a small amount of footage when news comes that the catastrophe is "inevitable in the next few hours", and they flee in a helicopter, filming the town from above: "we got the impression that these were the last hours of this town, and the last pictures ever taken of it". Herzog's rueful tone suggests the pride which the group took in this belief. This sequence, which allows minutes to pass without speech, is set to Rachmaninov; a choice which, like all the music used in the film (Brahms, Mendelssohn, Wagner -- unremittingly high-register), the viewer comes to understand as parodic once the non-event of the catastrophe has been announced. However, this pre-emptive and premature act of mourning is not simply ironic. The impression of a town temporally out of place, persisting after the population has fled, expands to take in that of a town which is spatially contested. The film highlights the prefecture's marginality to French society; on the periphery in relation to the métropole. The now abandoned Gendarmerie, Hôpital (with a fluttering Tricolor, clearly fraying at the edges long before this evacuation) and Banque Nationale de Paris are doubly out-of-joint, both as public buildings without a public, and as records of colonial imposition upon the landscape of Guadeloupe. It is tempting to describe the volcano, and thus the island, as preparing to reject those buildings -- to cast La Soufrière as a character in the drama of France and its former colonies. However, this is precisely the kind of anthropomorphic, ethical projection onto the landscape which catastrophe narratives employ, and which the non-event of catastrophe signals as essentially fictive.

Maximin's novel Soufrières confirms the power of this urge to site natural disaster in human drama. It is a temptation to which the characters in his novel are continually drawn, as they interpellate the volcano in the movement for independence from France, whilst mocking themselves for the narrative investments they make in La Soufrière. In the opening pages, which recount writer Marie-Gabriel's dream of 
eruption, we are warned that the volcano exceeds the meanings we try to attach to it:

Neither holy fire falling as divine punishment, nor maternal flood cleansing the earth of $\sin .[\ldots]$ what can it mean, this magma that takes twenty years, three centuries or two millennia to signal the next rendez-vous, time enough for the island to forget that it is ineluctable? (Maximin 1987, 11)

Despite her scepticism about projecting meaning onto the volcano, this dream of the desired and feared eruption also encodes the fear and desire she feels abo completing a novel inspired by the mother she never knew, and Marie-Gabriel disdains those who, rejecting all storyfication, cannot see that "tomorrow, here, cannot but be mythical [fabuleux]" (11). Adrien, writing from France to his friends regarding an adaptation of Wole Soyinka's Dance of the Forests (retitled for their production as Danse de la femme-volcan) that they are staging with their students in Guadeloupe, polemically declares that, if America is gently distancing itself, geographically and geologically, from Africa "which concedes 30 centimetres per decade $[\ldots]$ the Caribbean plate $[\ldots]$ pays for its resistance to this distancing with eruptions and earthquakes" (28-29). Marie-Gabriel, reading these lines, wryly remarks that Adrien's readers might guess that he is composing his words peacefully 7,000 kilometers away. Schoolteacher Inès, meanwhile, hopes in a statement at once ironic and sincere that La Soufrière will burn all the sugar plantations and spare their friend Rosan's co-operatively-run orchard (56), whilst at the close of the novel she gently rejects the "facile symbolism" of the toast given by Toussaint, in which he praises the "femmes-volcans d'ici" (226; our volcanowomen). Nixon argues that "place is a temporal attainment that must be constantly renegotiated in the face of changes that arrive from without and within, some benign, others potentially ruinous" $(2011,18)$. These examples from Soufrières demonstrate how the island's geological instability is given a global-historical interpretation: the 
precarious local, exemplified by the co-op, is subject to a triangular pull between America, Africa and France. During this period of physical instability, the characters are able to imagine the re-situation which appeals to them most -- making France foreign, getting closer to Africa -- whilst reminding each other that the volcano exceeds their metaphors.

Natural disasters have been central to global negotiations of the "place" of the Antilles since the beginning of the colonial era, and Soufrières also shows how political actors attempt to make the volcano an ally to their own political narratives. As Christopher Church (2017) notes in Paradise Destroyed, the disasters which hit the Caribbean in the late 19th and early 20th centuries provoked calls for the abandonment of the colonies as economically unviable. In Soufrières this long history is referenced by a Communist politician's speech, reported in the section of the novel entitled "Apostroh'Apocalypse", in which the hopes, fears and political interpellations of the volcano by a whole host of inhabitants are most clearly put. His speech interprets the volcano politically in order to assign blame: "le pouvoir colonial, de 1635 à nos jours, n’[a] jamais songé à organiser la vie du pays en fonction de sa nature géophysique" (Maximin 1987, 224; the colonial power, from 1635 to now, has never thought to organize life in the country according to its geophysics). Although the novel turns an ironic eye on such political opportunism, the statement highlights the problem discussed above. The "'risque zéro' pour les populations" (Beauducel 2015; zero risk for the population) demanded by the French President is incompatible with the requirement that societies under capitalism should be engaged in continuous production and consumption; concerns surrounding this requirement are evident in contemporary references to the need to sustain as long as possible "un minimum de vie économique", and in the evocation by those involved in the Nevado del Ruiz disaster of the 
“conséquences économiques dramatiques" (dramatic economic consequences) of the evacuation of Basse-Terre (Beauducel 2015).

As well as disrupting the economic productivity of Guadeloupe, the threatened catastrophe can be seen as offering an opportunity for metropolitan France to increase Guadeloupe's dependency on the mainland. Such a suggestion recasts evacuation: from a precaution that governments might be overly reluctant to take due to economic interests, to one which they might take too readily in the service of those same interests. Elsewhere in the "Apostroh'Apocalypse" section of the novel, the Head of Intelligence explains the "orders from Paris" to a volcanologist: "The eruption must leave one corpse only: the idea of independence!" (Maximin 1987, 176) ${ }^{8}$ A civil-servant friend of Rosan's, showcasing a dry sense of humour and an appreciation of the dramatic heritage of catastrophe, explains that the threat of eruption has arrived at just the right moment, harmonising with plans to relocate the administration of Guadeloupe to Pointe-à-Pitre, a large trading hub between Europe, the Caribbean and Latin America: "Between you and me, a little eruption would be perfect -- a real drama but not a bloody tragedy [ ... ] -just big enough to rattle the hardliners and make Basse-Terre's decline appear preordained" (85). Geological inevitability is harnessed by political machination so that a measure of inevitability can be imparted to ideology: it is narratives such as these that the novel encourages its readers to treat with suspicion. Ultimately, the volcano, susceptible to exploitation by both the state and those dreaming of independence, disappoints all hopes. As Maximin's volcanologist acidly responds to the Head of Intelligence, volcanos obey their own laws. What, then, do Herzog and Maximin offer in place of, or as an antidote to, narratives which seek to cast the potential eruption in the service of political factions?

\section{Singular narratives versus plural voices in La Soufrière}


The man whom Herzog seeks to interview occupies a comparable position to the characters in Maximin's novel, interpellating the eruption in a narrative which is thwarted by the failure of that eruption to actualize. When first found -- not alone after all, but with "two others" -- he has almost receded into the landscape. He sleeps peacefully in the heat of volcanic activity. When wakened, his responses invoke God and fate. Death or God waits for everyone, he says. Before this ultimate signifier, he assumes the character of an un-individuated mortal being. "It's God's will. [ ... ] no one knows when [death] will come, it is as God has commanded" (Herzog 1977). The camera turns to one of the "others", who echoes his companion. Asked by Herzog if he is afraid, he responds, "No, there is not a thing you can do. [ ... ] Yeah, the volcano, it's always up there above us". The literal volcano both is and is not the thing invoked in this statement.

The man on the mountain is deprived by the non-eruption of La Soufrière of the meaning he seeks: unification with God, through the volcano, in death. Herzog, too, is deprived of the tragedy he originally sought, and is left with something tainted by farce. If the expedition "ended a little bit embarrassing", is the mountain-man embarrassed? Surprisingly, the answer is: not in the least. The man's holy acceptance is humbling, even though some of his claims might provoke laughter. As the interview continues, he supplements the coming of the "inevitable" catastrophe with others: "I'm waiting for a typhoon too, that has been predicted. But I've lived through so many typhoons". At every turn, he exceeds the tragic narrative framing of the documentary: through his being not alone, but with companions; through his warmth and the songs he sings (the most beautiful moment of the film, starkly contrasting with the Rachmaninov or Wagner-accompanied landscape sequences); and through his easy reconciliation of abstract statements, oriented towards God and the eternal, and the more prosaic fact of 
his own poverty. This latter point orients us, in turn, towards a political reading of why certain individuals or populations are more precarious than others:

“I am waiting for death, and I wouldn't know where to go anyway, I haven't a cent. [ ... ] Death waits forever, it is eternal. [ ... ] Why should I leave? I would only have to come back. Where could I go?” (Herzog 1977)

If, when the film opens, it is captivated by the press story of the "one, single peasant" who has refused evacuation -- the kind of martyr story, or story of singular heroism, which Thomas Elsaesser $(1986,142)$ has identified as running through Herzog's works -- the presence of other non-evacuees means that a multiplicity of stories make their way into and overturn that initial narrative.

The man on the mountain has one particularly troubling counterpart: the man in the town. After Herzog and his cameramen descend the mountain, they encounter a man who has remained in Basse-Terre. His fear provides a dramatic contrast to the other's holy indifference, which he echoes but corrupts. The former says, "I have nothing, nothing at all, and I am waiting for death". The latter begins with, "I am not afraid of death, here I am, and I look after the animals". This confused statement of purpose -why look after animals which will die anyway? -- leads to a retraction: "and if it gets worse, if things get really bad, maybe I'll clear out today". Far from having nothing, he has a number of children evacuated safely to Pointe-à-Pitre, whom he would like to see again. The contrast suggests something clownish about this man, who is not an embodiment of benevolent holy poverty, but simply human. Nevertheless, his position is discomforting in a different, but similarly powerful manner. If the holy man is truly "waiting for an inevitable catastrophe" ("death will come"), the man in the town is apparently recoiling from an attempted act of bravery without clear purpose: "You can 
take me with you to Pointe-à-Pitre, if you like”. The view through the lens is deeply uncomfortable, here: there is something cruel in Herzog's voiceover translating and parroting the plea from the man in the town, with the camera pulling back from him, offering no response.

Through his encounters, Herzog -- his heroic projects chastened, as he is quite prepared to admit -- finds the moral that he came for, after all: "in my memory, it is not the volcano that remains, but the neglect and oblivion in which those black people live". Neither the mountain-man nor the town-man have been straightforwardly "saved" by the non-eruption of the volcano; the narratives they presented have unraveled; their existence continues, unknown to the viewer and without dramatic conclusion. In different ways, their poverty and their decision to remain stand as a reproach to the French government, whose slow violence is revealed to us in the spaciousness left by the absence of spectacular footage of an erupting volcano.

La Soufrière revolves around what it fails to show: spectacular images of catastrophic eruption. In order to explain the history of the evacuation, Herzog turns to the premediating story of the 1902 eruption of Mount Pelée on Martinique, thereby bringing yet more viewpoints into the space left in the parodied disaster-documentary that lacks a climax. Herzog traces the events in Saint-Pierre when, despite the signs emitted by the volcano, the governor encouraged the inhabitants to remain in the town to vote in an election (the disruption of economic and social life as ever at issue). When Mount Pelée, rather than erupting with lava, exploded in a pyroclastic surge (fastmoving gas at 1000 degrees centigrade), over 28,000 people were killed. Lacking any spectacular footage of eruptions, Herzog instead juxtaposes still photographs, the camera zooming in and out to mimic the flow of the deadly cloud, and evoking what he cannot show. We see a photograph of Saint-Pierre's destruction, with a ship sinking in 
the harbour and birds flying towards the photographer. We hover over this image, as Herzog insists on its reality: "this is not a painting".

Herzog goes on to tell us, repeating the rhetorical surplus of the "one, single peasant", that there was "one survivor -- just one". He was Louis-Auguste Cyparis, "the baddest guy in town", who was in prison at the time of the eruption. There were 70 prisoners, but he was "the only one that behaved so badly [ ... ] that, as punishment, he was placed in an underground solitary confinement". After his rescue and convalescence, he toured the US in a freak-show, with crowds gawping at the scars that covered his back. Cyparis is a marginal figure, a survivor but a living ghost; a role that the survivor can all too easily be forced to play. To survive is to risk losing the previous narrative multiplicity of a life -- to risk being subsumed by the catastrophe which one has supposedly escaped into a narrative which, whilst encompassing singular experience, belongs to the world at large: to the global spectator. This usurpation of identity is made clear by Cyparis's change of name to Ludger Sylbaris (more amenable to anglophone pronunciation). In highlighting this story, the documentary adds another strand to the successful parody of its own opening bombast, encouraging the viewer to reflect on the way that the spectacle of catastrophe narrows the lives caught up in it -- to borrow Nixon's terms, both Cyparis's life and the story of the violence of the eruption are shrunk to a "story unit" that has no greater duration that that of the pyroclastic surge.

The documentary does, nevertheless, fall back on some of the tropes of the singular and spectacular that it had seemed to parody. Cyparis, as has always been known, was not the only survivor of the eruption. To insist on his uniqueness is to replicate his characterization in Barnum's Circus as "the only living object [sic] that survived in the Silent City of Death" (Scarth 2002, 189; see 127-136 for details of other survivors). Herzog is reconstructing a past in the present to offer a coherent explanation 
as to why a town would ignore the most unequivocal warning signs and fail to evacuate, and why only one man might survive. But he is also using that past catastrophe to reconstruct a present one which has disappointingly failed to actualize. The elisions and omissions in Herzog's use of Cyparis's story indicate a reluctance to relinquish the narrative of the lone hero: Cyparis is proclaimed sole survivor as the anti-heroic mirror image to the man on the mountain, who should have been the lone, tragic death in the present catastrophe, but who turned out to be neither alone, nor fated to die. Cyparis's fabricated singularity - "the baddest guy in town" -- supports the belied-even-as-upheld singularity of the man on the mountain. Herzog repeats this claim in his return to the subject of volcanic eruption, Into the Inferno (Herzog 2016), in which his collaborator Clive Oppenheimer echoes Herzog's reduction of Cyparis to the unique, worst, "baddest guy".

And yet, returning to Nixon's privileging of writing over film, the elements of La Soufrière which challenge the clichés of catastrophe narratives (over-emphatic music of the kind that might accompany a genuinely spectacular shot, deployed as parody, or, by way of contrast, lingering shots without action and photographic collages which are markedly unspectacular) are far more grounded in the medium than is the temptation to a narrative of singularity. Narratives of tragedy and heroism are most effectively targeted by the most visual, least narrative passages of the film. The Rachmaninov flyover sequence gives us the familiar tragic mode, but is undermined as the documentary proceeds. The sequence which follows this, descending into and exploring the town, deploys collage and silence to produce a clear candidate for one of Nixon's “iconic symbols that embody amorphous calamities" by overturning a state-sponsored symbol. The camera, after taking in the Banque Nationale de Paris and hôpital in its ironic elegy, lingers immobile for 13 long seconds on the monument to Guadeloupe's World War 
dead. The viewer has ample time to reflect on the inscription:

\section{LA GUADELOUPE}

\section{A SES ENFANTS}

\section{MORTS POUR LA FRANCE}

Thanks to this lingering slowness, the commemorative force of the monument takes on a political charge. The wording does not differ from that found on monuments all over France, but the relationship to the nation does: Guadeloupe both is and is not interpellated by LA FRANCE. The monument commemorates the people, historically displaced by a colonising nation, called to the heart of a European catastrophe to fight and die as part of that same nation. Herzog's framing of the monument within the documentary invites us to think beyond the years bounded by the war (as Nixon wished to do when discussing victims of Vietnam), and to see this monument as one connoting the "amorphous calamities" of inequality and precariousness that form the legacy of colonialism. The possibility of presenting multiple readings of such a monument, challenging univocal narratives and spectacular climaxes, whether in film or literature, is what allows us to seek models for the portrayal of slow violence in such works.

\section{Creativity and non-parodic life in Soufrières}

In Maximin's novel, language, like the volcano, is manipulated by both the administration and those who resist. The Director of Intelligence in Guadeloupe, whom we can assume was born and educated in mainland France, is both ridiculous and threatening with his half-baked understanding of local culture:

It was his custom, whenever he arrived in a new post -- he who had "done Africa" -- to throw himself into a volume of local proverbs which, in his opinion, held the key to the enigma of unknown or uncategorisable peoples, like 
the Antilleans. (Maximin 1987, 87)

The deformation and simplification of Antillean language and culture by the administration -- its rendering as mere parody of French -- is encapsulated in the same Director's lazy application of a creole proverb to the evacuation: "Sakrifié dèyè pou vwè douvan" (177; Sacrifice what's behind to see ahead). In a society which places a high value on its runaway nègre marron heritage, the associations of this proverb far surpass the Director's understanding.

And yet, it is through language, and creative work in particular, that the text allows its characters to imagine - in the words of Marie-Gabriel's crucial opening dream -- "la naissance des jours sans parodies de vraie vie" (Maximin 1987, 12; the birth of days without parodies of real life). When émigré Adrien arrives back in Guadeloupe from France, before joining the friends who have longed for his arrival, he offers to drive Mme. Roussy, an elderly lady encountered on the plane, to her old home in the evacuated zone. She had intended to recover the ashes of her son, killed under the Vichy government during World War II, but decides at the last moment to scatter them on the slopes of the volcano. Driving back, they pass through deserted Basse-Terre and witness an American film crew floodlighting the streets to capture footage of the empty town (194-206). This sequence encapsulates the way that Maximin's novel stages the "production" of natural catastrophe narratives in the pernicious manner described by Nixon, in which political interests can hide themselves. The novel also explores the time under the threat of eruption as one of great creativity, which in turn might have the power to heal old traumas. Mme. Roussy herself reads Adrien's copy of MarieGabriel's manuscript during the flight, and attributes her sudden decision to relinquish her son's ashes to the landscape to a "wearing away of old chains" (204) enacted by that text. 
This is just one example of the power attributed to creative works in a text that teems with a multiplicity of voices and citations, offering diverse interpretations of catastrophes natural, political and personal. The novel includes diaries, dreams, poems and other fragments written by the characters, as well as a section in the voice of the volcano itself. Its intertexts range from André Schwarz-Bart's (1972) La mûlatresse Solitude, to the works of Cuban artist Wifredo Lam, the poetry of Henri Michaux, and South African jazz. Through literary intertexts, the novel traces the catastrophes which are also its intertexts, or premediators. I cannot here do justice to the personal histories of every character, or to the global literary community that the novel invokes, but shall discuss three events which are particularly important in the text, and which expand the "story unit" of the potential eruption in three directions. The eruption of Mount Pelée is referenced (Maximin 1987, 55), but the novel looks beyond this twinned spectacular image to situate the events around the non-eruption of La Soufrière in relation to the reimposition of slavery under Napoleon, to events unfolding in Soweto, Johannesburg in 1976, and to the massacre of Mé '67.

The import of this referencing of catastrophes past and unfolding is that each of the characters has already suffered disaster. Explicit here, and only implicit in Herzog's film, is the fact that many subjects already live in an aftermath; Guadeloupe is already a post-catastrophe society (Bongie 1994, 633). This is evident in the opening of the third section, which quotes Adrien's diary: “Avignon. You hear the sound of a terrible explosion on the volcano, catapulting ten straw dummies of Empire troops into the sky" (Maximin 1987, 119). The presumed-imminent eruption of La Soufrière is here linked to the suicide bomb set at the Mantouba Plantation in 1802 by Louis Delgrès, the Guadeloupe rebel leader resisting the attempted Napoleonic reimposition of slavery. That event is recreated as part of a (real, historical) stage adaptation of Schwarz-Bart's 
La mûlatresse Solitude. Both the adaptation of this Jewish-authored "roman antillaise", and the "pièce africaine" which has been rewritten as the Danse de la femme-volcan, are performed in the shadow of La Soufrière, and all that her potential eruption means to the characters. As Adrien writes of the latter piece, "La Soufrière does not disarm us; rather, she demands that we urgently consider our position relative to our masks [nous situer par rapport à nos masques]" (28).

In Herzog's documentary, there was at times something cruel about the use of English-language voiceover, obscuring the interviewees' own words. Conversely, in Maximin's novel, English - ironically, because of the reach of a anglophone imperialism -- is a language of global resistance, and of solidarity with those being massacred at Soweto. The uprisings at Soweto concerned the imposition of the Afrikaans language for certain school subjects, with English preferred by schoolchildren protesting against the local "language of the oppressor". ${ }^{9}$ Adrien, preparing to leave for Guadeloupe, drives a distraught young South African man to the airport. They listen to music on the way, and the grateful passenger translates the image of a cleansing volcano from Xhosa into English "comme en salut fraternel”: "The volcano in its crater is fire enough to cremate the ghetto's creators" (Maximin 1987, 76). Such passages reveal how complex and shifting is the triangle which pulls Guadeloupe towards France, Africa and the anglophone world.

But the event which casts its shadow over the greatest number of characters is from 1976's mirrored year -- 1967. The massacre of Mé '67 rendered the group of friends depicted in Soufrières viscerally conscious of their subjugation by metropolitan France. Depicted as itself catastrophic, the event has wrought slow violence over the ensuing decade. Mute Elisa has not spoken since her brother died in her arms that day. Toussaint, at the time happily married to a white woman with whom he has a child, 
sank into alcoholism and despair. As he explains to Elisa:

On the same day as you, I too received a wound, one which left no trace on my body, [ ... ] in opposition to what happened to you, words started pouring out of me, others' words, words from books [ ... ]; and that is a terrible affliction. (Maximin 1987, 211)

Amongst the group, it is Toussaint who embodies parody: his alcoholism borrows a lyrical sheen from Léon Damas’s Black-Label (1956), and he avoids direct communication by ventriloquising Henri Michaux at every opportunity. His longing for cataclysmic, violent revolution provides the only escape route he can imagine: in this novel, the explosive power of the volcano is at once what the characters are exposed to by slow and structural violence, and a fantasized escape from oppression. The novel leaves open the question of whether Toussaint will take this exit, accomplishing his fantasy of driving his car, packed with stolen plastic explosive, into a sugar truck (264265). We are invited to compare this bomb to that set by Delgrès, or the cleansing volcano evoked in the song translated by Adrien's South African passenger. On the other hand, he may start to heal, as does Elisa, who ends the novel having found in books a path back to speech (209-210).

Rather than a volcanic eruption, it is a fire at Marie-Gabriel's home that closes the novel (Maximin 1987, 267). Elisa escapes with a reproduction of Lam's The Jungle, the music collection which is all that Marie-Gabriel has of her father, and that maternalinspired novel which Toussaint's ex-wife Ariel describes thus: "It reconciles the face with the mask [ ... ]. A song for ten voices, a theatre for a hundred voices, a poem for two voices" (165). For this group of friends, ruinous eruption represents an impossible desire to begin anew, to shed their personal and national past: to be reborn as Antillean, 
not French or African, or more precisely, not as not-French, or not-African.

Composition and creativity offer the slender possibility of reconciliation, as MarieGabriel writes to Elisa:

You and I, we had nothing and we lost everything, but this madness is more fruitful to the crafting of a future [pour composer un avenir] for our island, with its treasures of fire in the volcano, of air in tornadoes, of earth in quakes and of water in tidal waves. (122)

Crucially, any such "reconciliation" is not effected by finding one true, coherent, antiparodic narrative, but by maintaining a plurality of voices and stories which offer multiple views on a single event, and also expand the "story unit" of that event in multiple directions: knowing the face through masks, not by unmasking.

\section{Writing vs film?}

Soufrières reveals that there are multiple ways of narrating catastrophe, and that the meanings we construct around catastrophe are never straightforward. Through Herzog's film and Maximin's novel, we see that pre- and re-mediating narratives are contingent upon the event of catastrophe, and that they are thus always potentially open to embarrassment -- though an embarrassed narrative may tell us more than a successful one about underlying structures of violence within a society at risk. With recent catastrophes like the 2009 L'Aquila earthquake, where blame was assigned to scientists who claimed that unenforced building regulations were the true problem (reported by the BBC on 16 September 2011), it is clear that those assigned to deal with the aftermath tend to privilege narratives that focus on individual responsibility over those involving structural violence. Perhaps such narrative simplifications do flourish in the medium of the visual, which Nixon advised us to "challenge", embracing the 
complexity of writing. Nevertheless, I will make two points against any hierarchization of these media in the vital task of making "slow violence visible" whilst "challenging the privileging of the visible".

The first is that, although Herzog's documentary involves simplifications not present in Maximin's novel, many of the elements of La Soufrière which most effectively point to the slow violence of colonialism are medium-specific. The second is that the staging of multiple voices and multiple narratives serves the portrayal of slow violence in both works, irrespective of medium. The documentary does this most successfully when it parodies its own genre. Narratives which go nowhere -- either because the catastrophe does not occur, or because it does not take place in the form predicted by that narrative -- usually become invisible. They are either forgotten, as Herzog expects that "the volcano will soon be forgotten", or are subsumed into the “correct" explanation which teaches survivors and witnesses why those narratives are, and always were, false. The film, exposing what is usually hidden, leads us to the question of who the narratives built around catastrophe are for. The novel juxtaposes parody -- displayed naively by the Director of Intelligence, or lived as an "affliction" by Toussaint -- alongside the imperative to non-parodically cite, rewrite, and create a literature of the Antilles, with which Marie-Gabriel, Adrien, Elisa, and those staging the Danse de la femme-volcan or La mûlatresse solitude all engage. The characters must embrace a kind of double-think: living the metaphor of the volcano in order to survive their personal and shared traumas (being a soufrière), whilst also recognising that the reality of the volcano escapes them, and refusing those narratives which would reduce it to a pawn in a political game. I will close by citing this caution, from Adrien's journal but echoed later (Maximin 1987; 152) by the volcano itself. This passage takes aim at all the investments in the volcano depicted by the novel, as well as the novel itself: "La 
Soufrière is not a setting for a novel. [ ... ] La Soufrière is not a bomb in the service of historical progress. She does not care about our history: she is our geography" (125).

\section{Notes on contributor}

Jessica Stacey holds a PhD in French Literature from King's College London. She is currently a Career Development Fellow at The Queen's College, University of Oxford. Her major research interest is in the way that our concepts of time and civilisational change are shaped by metaphor and narrative, particularly as these pertain to catastrophes.

\section{Acknowledgements}

This research was supported by a Crompton Scholarship and by the Arts and Humanities Research Foundation. The article has benefitted from the input of many friends and colleagues; I would particularly like to thank Nicholas Harrison, Joseph La Hausse de Lalouvière, Sanja Perovic, and Robert Stearn, who all read and commented on the piece in its earlier incarnations. I would also like to thank the reviewers and editorial team of the Journal of Postcolonial Writing, whose input has been similarly transformative.

\section{References}

Beauducel, F. [2006] 2015. À propos de la polémique "Soufrière 1976". http://www.ipgp.fr/ beaudu/soufriere/forum76.html

Bongie, Chris. 1994. "The (Un)Exploded Volcano: Creolization and Intertextuality in the Novels of Daniel Maximin." Callaloo 17 (2): 627-642.

Church, Christopher. 2017. Paradise Destroyed: Catastrophe and Citizenship in the French Caribbean. Lincoln, NE: University of Nebraska Press.

Damas, L.-G. 1956. Black-Label: Poèmes. Paris: Gallimard.

Elsaesser, Thomas. 1986. “An Anthropologist's Eye: Where the Green Ants Dream.” In The Films of Werner Herzog: Between Mirage and History, edited by Thomas Corrigan, 133-156. New York and London: Methuen.

Erll, Astrid. 2008. "Literature, Film and the Mediality of Cultural Memory.” In $A$ Companion to Cultural Memory Studies, edited by Astrid Erll and Ansgar Nünning, 3893-3898. Berlin: De Gruyter. 
Herzog, Werner, dir. 1977. La Soufrière: Warten auf eine unausweichliche Katastrophe [La Soufrière: Waiting for an inevitable catastrophe]. Guadeloupe and Germany: Werner Herzog Filmproduktion.

Herzog, Werner, dir. 2016. Into the Inferno. UK, Austria: Matter of Fact Media, Spring Films and Werner Herzog Filmproduktion.

Horn, Mike, dir. 2017. Mai 67, ne tirez pas sur les enfants de la République. France: Art 2 voir and Step by Step Productions.

Hough, Susan. 2009. "Confusing Patterns with Coincidences." The New York Times, April 11. http://www.nytimes.com/2009/04/12/opinion/12hough.html?_r=0

Maximin, Daniel. 1987. Soufrières. Paris: Seuil.

Nixon, Rob. 2011. Slow Violence and the Environmentalism of the Poor. Cambridge, MA: Harvard University Press.

Scarth, Alwyn. 2002. La Catastrophe: Mount Pelée and the Destruction of Saint-Pierre, Martinique. Harpenden: Terra Publishing.

Schwarz-Bart, André. 1972. La mûlatresse Solitude. Paris: Seuil.

\section{Notes}


${ }^{1}$ Between May 26 and 28, 1967, the French government violently repressed a demonstration by construction workers in Guadeloupe. The official tally of eight victims has long been contested.

${ }^{2}$ All translations from Soufrières are my own.

${ }^{3}$ This question is closely wrapped up with that of identity in the novel, as Bongie (1994) suggests. For him, Maximin registers "the continued necessity of thinking in essentialist terms [whilst stressing] the essentially fictive nature of what he is (re)constructing" (629).

${ }^{4}$ Psychiatrist Aimé Charles-Nicolas, interviewed in Mike Horn's documentary on the massacre (Horn 2017), interprets the silence of victims in terms of fear based on suffering related to slavery.

${ }^{5}$ The evacuation officially began on August 15, when 40,000 were removed from the island, and did not end island-wide until December 1.

${ }^{6}$ The affair is documented in the excellent resource compiled by F. Beauducel (2015), who led the seismicity observation team on Guadeloupe between 2001 and 2007.

${ }^{7}$ For a recent example of how narratives of blame and responsibility play out when a catastrophe does occur, we can look to the 2009 earthquake near L'Aquila, Italy. A group of earthquake scientists (who in turn blamed the devastation on the failure to enforce building regulations) was judged responsible for the disaster and convicted of involuntary manslaughter in 2012, only to have their convictions quashed in 2015. See Susan Hough (2009) for an early intervention into the case, and an analysis of the mutual incomprehension that exists between scientists, civil servants and the public around the problem of "prediction". She resumes the problem of caution versus the avoidance of disruption thus: "We do know that some earthquakes, including the L'Aquila event, have foreshocks, but we can't sound alarm bells every time little earthquakes happen because the overwhelming majority -- 95 percent or so -- will not indicate a coming major quake.” (n.p.)

${ }^{8}$ This represents a simplified, unidirectional version of the relationship described by Church (2017, 233246) between earlier disasters and the movement for greater integration.

${ }^{9}$ These are the words of Desmond Tutu. See http://www.economist.com/blogs/johnson/2012/08/language-south-africa. 